\title{
ANALYSIS OF THE CORRELATION BETWEEN PROJECT STRATEGY AND IMPACT FACTORS OF RESEARCH AND DEVELOPMENT PROJECTS
}

\author{
ANALIZA CORELATIEI DINTRE STRATEGIA DE PROIECT ŞI FACTORII DE IMPACT AI PROIECTELOR DE \\ CERCETARE-DEZVOLTARE
}

\author{
Margareta FLORESCU ${ }^{1 *}$, Gheorghe COARĂ², Luminiţa ALBU ${ }^{2}$ \\ ${ }^{1}$ The Bucharest Academy of Economic Studies, Bucharest, Romania, icefaceus@yahoo.com \\ ${ }^{2}$ INCDTP - Division Leather and Footwear Research Institute, 93 Ion Minulescu, sector 3 Bucharest, Romania, icpi@icpi.ro
}

\begin{abstract}
ANALYSIS OF THE CORRELATION BETWEEN PROJECT STRATEGY AND IMPACT FACTORS OF RESEARCH AND DEVELOPMENT PROJECTS
ABSTRACT. Due to increasingly higher influences of science and technology in the industrial sector on national economy, national funds were created in different financing programs for research and development (R\&D) projects. Many studies were carried out to evaluate performance of such R\&D projects. This paper deals with the implementation of project strategy to improve performance of developing a new product in project activity, to analyse the short-, medium- and long-term performance relationship among impact factors of R\&D projects in the industrial field. The importance of developing project strategy was one of the major issues both for the industry and for academic fields. In many cases, project strategy is not well developed for large and complex projects. The results of this paper are expected to contribute to a better understanding of the impact of financing through R\&D projects, by validating a model to evaluate relationships between implementing project strategy, results of the R\&D project and performance of results on the market.

KEY WORDS: project management, strategy, impact, financing
\end{abstract}

ANALIZA CORELATIEI DINTRE STRATEGIA DE PROIECT ŞI FACTORII DE IMPACT AI PROIECTELOR DE CERCETARE-DEZVOLTARE

REZUMAT. Datorită influenţelor crescute ale ştiinţei şi tehnologiei în sectorul industrial asupra economiei naţionale, s-au creat fonduri naţionale pe diferite programe de finanţare pentru proiectele de cercetare şi dezvoltare (C\&D). Numeroase studii au fost efectuate pentru a evalua performanţa unor astfel de proiecte de C\&D. În această lucrare, vom trata implementarea strategiei de proiect pentru îmbunătăţirea performanţei dezvoltării unui nou produs în activitatea de proiect, pentru a analiza relaţia de performanţă pe termen scurt, mediu şi pe termen lung între factorii de impact ai proiectelor de C\&D în domeniul industrial. Importanţa dezvoltării strategiei proiectului a fost una dintre problemele majore, atât pentru industrie, cât şi pentru domeniile academice. Strategia de proiect, în multe cazuri, nu este bine dezvoltată pentru proiecte mari şi complexe. Rezultatele acestei lucrări sunt de aşteptat să contribuie la o mai bună înţelegere a impactului finanţării prin proiecte C\&D, prin validarea unui model pentru evaluarea relaţiilor dintre punerea în aplicare a strategiei proiectului, rezultatele proiectului de cercetaredezvoltare şi performanţa rezultatelor asupra pieţii.

CUVINTE CHEIE: management de proiect, strategie, impact, finanţare

L'ANALYSE DE LA CORRÉLATION ENTRE LA STRATEGIE DU PROJET ET LES FACTEURS D'IMPACT DES PROJETS DE RECHERCHE ET DÉVELOPPEMENT RÉSUMÉ. En raison des influences de plus en plus élevées de la science et de la technologie dans le secteur industriel sur l'économie nationale, des fonds nationaux ont été créés dans les divers programmes de financement pour la recherche et développement (R \& D). De nombreuses études ont été réalisées pour évaluer la performance de ces projets de R \& D. Cet article traite de la mise en œuvre de la stratégie de projet pour améliorer les performances de développer un nouveau produit de l'activité de projet, d'analyser la relation de la performance à court, moyen et long terme entre les facteurs d'impact de projets de R \& D dans le domaine industriel. L'importance de l'élaboration de la stratégie du projet a été l'un des principaux problèmes à la fois pour l'industrie et pour les domaines académiques. Dans de nombreux cas, la stratégie du projet n'est pas bien développée pour les grands et complexes projets. Les résultats de cette étude devraient contribuer à une meilleure compréhension de l'impact du financement par les projets de R \& D, par la validation d'un modèle pour évaluer les relations entre la mise en œuvre de la stratégie de projet, les résultats du projet de R \& D et la performance des résultats sur le marché.

MOTS CLÉS: gestion de projet, stratégie, impact, financement

\section{INTRODUCTION}

Science and technology are the most important motivators of a country to improve and strengthen the national economy in the global competitiveness. Project strategy is the direction in a project that contributes to the success of the project in its environment [1].

\section{INTRODUCERE}

Ştiinţa şi tehnologia reprezintă cei mai importanţi factori motivatori ai unei ţări pentru a-şi îmbunătăţi şi consolida economia naţională la nivelul competitivităţii globale. Strategia de proiect este o direcţie într-un proiect care contribuie la succesul proiectului în mediul său [1].

* Correspondence to: Margareta FLORESCU, The Bucharest Academy of Economic Studies, Bucharest, Romania, icefaceus@yahoo.com 
Many studies have shown that project strategy can contribute to project performance in terms of its cost, schedule, and operational characteristics [2]. The project strategy is critical to the success of all types of projects. Developing project strategy is one of the most important tasks during project planning. Just as business strategy refers to the company's aspiration to achieve a desired position in its external competitive environment, project strategy refers to the aspirations of a project to achieve a desired position in the competitive environment of stakeholders.

The literature has largely ignored the impact of project strategy on its success. In recent years, there has been a tendency to develop project strategy regarding its results: products, new technologies, experimental models, product approvals. Research institutes have adopted best practices for project strategy development in an attempt to reduce material, financial and human resources costs in these projects. Equally, these public institutions are also considering how to improve innovation performance.

The main objective of this study was to validate a model for evaluating relationships between project strategy implementation, project results and their performance on the market. A data collection instrument was developed to evaluate the strategy of adopting projects and their scientific results. This research was designed to include strategies thought out to have a substantial impact on R\&D projects.

\section{CONCEPTUAL FRAMEWORK AND RESEARCH HYPOTHESES}

Previous research studies define project strategy as being mostly about targets and plans and argue that these targets and plans are aligned with the strategy of the organization that manages the project. For a research, development and innovation project, success is highlighted by how well the project is able to achieve its targets in terms of project results (including performance measured by indicators, cost, quality and innovation) and the ability to market the project results.
Multe studii au arătat că strategia de proiect poate contribui la performanţă proiectului, în ceea ce priveşte caracteristicile de cost, program şi cele operaţionale [2]. Astfel, strategia proiectului este esenţială pentru succesul proiectelor de toate tipurile. Elaborarea strategiei de proiect este una dintre cele mai importante sarcini în perioada de planificare a proiectului. Aşa cum strategia unei firme se referă la aspiraţiile firmei de a obţine o poziţie dorită în mediul său extern concurenţial, strategia unui proiect se referă la aspiraţiile proiectului pentru a obţine o poziţie dorită în mediul concurenţial al părţilor interesate.

Literatura de specialitate a ignorat în mare măsură impactul strategiei de proiect asupra succesului acestuia. În ultimii ani, a existat o tendinţă de dezvoltare a strategiei proiectului privind rezultatele acestora: produse, tehnologii noi, modele experimentale, omologări de produse. Institutele de cercetare au adoptat cele mai bune practici în dezvoltarea strategiei de proiect în încercarea de a reduce costurile materiale, financiare şi umane din aceste proiecte. În aceeaşi măsură aceste instituţii publice examinează, de asemenea, modalităţile de a îmbunătăţi performanţa de inovare.

Obiectivul principal al acestui studiu a fost de a valida un model pentru evaluarea relaţiilor dintre punerea în aplicare a strategiei proiectului, rezultatele proiectelor şi performanţa acestora de piaţă. Un instrument de colectare a datelor a fost dezvoltat pentru a evalua strategia de adoptare a proiectelor şi rezultatele ştiinţifice ale acestora. Această cercetare a fost concepută pentru a include strategii care au fost gândite spre a avea un impact substanţial asupra proiectelor C\&D.

\section{CADRUL CONCEPTUAL ŞI IPOTEZELE DE CERCETARE}

Cercetările anterioare consideră că strategia de proiect este, în mare parte, despre ţinte şi planuri şi argumentează că aceste ţinte şi planuri sunt aliniate cu strategia organizaţiei care gestionează proiectul. Pentru un proiect de cercetare-dezvoltare-inovare, succesul este evidenţiat prin cât de bine proiectul este capabil să-şi atingă ţintele din perspectiva rezultatelor proiectului (incluzând performanţa măsurată prin indicatori, cost, calitate şi inovaţie) şi capacitatea de marketing a rezultatelor din proiecte. 
Most of the literature dealing with the topic of project management focuses on the technical and execution tools rather than on effective development and project strategy development within a broader concept of the process. Previous studies have shown that the implementation of projects based on strategies increases the efficiency of the whole process of strategic management. The effectiveness of management activities of the partner institution or project coordinator is increased by introducing the business strategy implementation plan. In addition, how the strategy is successfully implemented through projects is also an important issue in project management. The findings show that the link between the strategic process and project management is defined as a success factor. Project management plays a strategic role in a company. On the other hand, other recent works have developed models of strategic management and provided an analysis of the project strategy. A model was developed by Anderson and Merna [2] showing how this places project management in the context of business development. The model can help create a project strategy. In addition, Qureshi et al. [3] created a model for assistance in measuring project management performance. They concluded that the project management strategy has strong positive correlations with performance of project management. It is one of the practices that show dominant impact on project performance. In conclusion, previous studies provide valuable knowledge regarding project strategy and methods that can be used in developing a new strategy.

For a strategy to be perfectly deliberate - for the strategy to be carried out exactly as it was intended to be created - at least three conditions must be met:

1 ) the organization must have precise intentions, articulated in a relatively detailed manner, so that there would be no doubt as to what was meant to be done before any type of action is taken;

2 ) as the organization requires collective action, it is very important to disperse any possible doubt about the intentions, whether they are organisational or not, so all stakeholders must have the same intentions;

3 ) these collective intentions must be carried out exactly as planned, which means that no external force
Majoritatea literaturii de specialitate ce tratează tema managementului de proiect îşi concentrează atenţia pe instrumentele de execuţie şi tehnică mai degrabă decât pe dezvoltare eficientă şi dezvoltarea strategiei proiectului în cadrul unui concept de proces mai larg. Studiile anterioare au arătat că implementarea proiectelor bazate pe strategii determină creşterea eficienţei întregului proces de management strategic. Eficienţa activităţilor de management din întreaga instituţie parteneră sau coordonatoare a proiectelor este crescută prin introducerea planului proiectului de implementare a strategiei de business. În plus, modul în care se implementează strategia cu succes prin intermediul proiectelor este, de asemenea, o problemă importantă în managementul proiectelor. Descoperirile arată că legătura dintre procesul strategic şi managementul de proiect este definită ca un factor de succes. Managementul de proiect joacă un rol strategic într-o companie. Pe de altă parte, alte lucrări recente au dezvoltat modele de management strategic şi au furnizat o analiză a strategiei proiectului. A fost dezvoltat de către Anderson şi Merna [2] un model şi modalitatea în care acesta plasează managementul de proiect în contextul dezvoltării unei afaceri. Modelul poate ajuta la crearea unei strategii de proiect. În plus, Qureshi şi colab. [3] au creat un model de asistenţă în măsurarea performanţei managementului de proiect. Aceştia au ajuns la concluzia că strategia managementului de proiect are corelaţii puternice pozitive cu performanţa managementului de proiect. Este una dintre practicile care arată impactul dominant asupra performanţelor proiectului. În concluzie, studiile anterioare furnizează cunoştinţe valoroase în ceea ce priveşte metodele şi strategia proiectului, care pot fi folosite în dezvoltarea unei noi strategii.

Pentru ca o strategie să fie perfect deliberată - ca strategia realizată să fie exact aşa cum s-a intenţionat a se crea - trebuie să fie îndeplinite cel puţin 3 condiţii:

1) trebuie să existe intenţii precise în cadrul organizaţiei, articulate într-un nivel relativ de detaliere, pentru a nu exista dubii referitor la ceea ce s-a dorit a fi realizat înainte de a întreprinde vreun tip de acţiune;

2) pentru că organizaţia presupune acţiuni colective, a dispersa orice îndoială posibilă referitor la intenţii, dacă sunt sau nu organizaţionale, este foarte important, aşa că trebuie că intenţiile tuturor actorilor implicaţi să fie aceleaşi;

3) aceste intenţii colective trebuie să fie realizate exact aşa cum au fost planificate, ceea ce înseamnă că 
(marketing, technological or political) should interfere with them. On the other hand, for a strategy to be perfectly emergent, there must be a certain order - a coherence of actions over time - in the absence of intent related to it.

From a variety of strategies that are part of this process, starting with those closest to deliberation and ending with those that best reflect the characteristics of emerging strategies, the following were selected: planned strategy, entrepreneurial strategy, ideological strategy, umbrella strategy, process strategy, strategy without connections, strategy without consensus, and imposed strategy. The strategy used in this study meets the first and the second condition of a fully deliberate strategy. However, one of the strategy costs (using new technology and equipment that can reduce costs) does not meet the third condition. Specifically, an external force (technology) might interfere with the strategy. Cost strategy regarding the use of equipment and technologies that can reduce production costs can be influenced by technological force. While the strategy of a project may tend more towards deliberate and emergent strategies rather than towards a single type, the strategy evaluated in this study is closer to the deliberate type.

While the authors mentioned above promote the adoption of project strategies, other researchers were also interested in exploring the impact of strategy formulation on project success. Thompson [4] also provides evidence showing the relation between quality of strategy and three types of project results. As shown from literature review, strategic planning plays an important role in a project. It is an important component of an effective project management. Problems related to the adoption of a strategy are the leading cause of the effect of the project. However, most project strategies were difficult to identify and some were not clear or well organized. The causes of poor performance usually have their origin in poor management, especially in stage of strategy formulation and less in the execution phase. If a problem is detected during strategy formulation, many other problems are minimized in subsequent steps. The formulation stage is thus often recognized as the most important and most difficult phase of a project. The results of previous studies indicate a correlation nicio forţă externă (de marketing, tehnologică sau politică) nu trebuie să interfereze cu ele. Pe de altă parte, pentru ca o strategie să fie perfect emergentă, trebuie să existe o anumită ordine - o coerenţă a acţiunilor de-a lungul timpului-în lipsa unor intenţii legate de aceasta.

Dintr-o varietate de tipuri de strategii care se încadrează în acest proces, începând cu cele aflate cel mai aproape de deliberare şi terminând cu cele ce reflectă cel mai bine caracteristicile strategiilor emergente, au fost selecţionate următoarele: strategie planificată, strategie antreprenorială, strategie ideologică, strategie de tip umbrelă, strategia de proces, strategia fără conexiuni, strategia fără consens şi strategia impusă. Strategia folosită în acest studiu satisface prima şi a doua condiţie ale unei strategii complet deliberate. Totuşi, unul dintre costurile strategiei (folosind tehnologie şi echipamente noi care pot reduce costurile) nu întruneşte cea de-a treia condiţie. Mai exact, o forţă externă (forţă tehnologică) ar putea să interfereze cu strategia. Strategia de cost în ce priveşte folosirea unor echipamente şi tehnologii care pot duce la reducerea costurilor de producţie poate fi influenţată de forţa tehnologică. În timp ce strategia unui proiect poate avea tendinţe mai mult în direcţia unor strategii deliberate şi emergente decât în direcţia unei singure forme, strategia evaluată în acest studiu se apropie mai mult de forma deliberată.

În timp ce autorii menţionaţi anterior promovează adoptarea unor strategii de proiect, alţi cercetători s-au preocupat, de asemenea, de explorarea impactului formulării strategiei în succesul proiectului. Thompson [4] oferă, de asemenea, dovezi care arată legătura dintre calitatea strategiei şi trei tipuri de rezultate ale proiectelor. Aşa cum arată analiza literaturii, planificarea strategică joacă un rol important în cadrul unui proiect. Este o componentă importantă a unui management de proiect eficient. Problemele legate de adoptarea strategiei sunt principala cauză a efectului proiectului. Totuşi, majoritatea strategiilor de proiect au fost dificil de identificat şi unele nu au fost clare sau bine organizate. Cauzele unei performanţe slabe îşi au de obicei originea într-un management slab, în special în etapa de formulare a strategiei şi mai puţin în cea de execuţie. Dacă o problemă este identificată în timpul formulării strategiei, multe alte probleme sunt reduse în etapele următoare. Astfel, faza de formulare este deseori recunoscută ca cea mai importantă, dar şi cea mai dificilă fază a unui proiect. Rezultatele studiilor 
between the adoption of the strategy (including differentiation, cost, operational and quality strategies) and project performance. In addition, previous research has found that marketing performance reflects external success and project performance reflects the internal success. A literature review also shows that the success of the project can be seen as an internal success that later leads to marketing performance. On the basis of the relevant literature, the following hypotheses have been postulated and tested:

- Hypothesis 1: Implementation of a strategy of differentiation positively influences outcomes of $R \& D$ projects in the industrial sector.

- Hypothesis 2: Implementation of cost strategies positively influences outcomes of R\&D projects in the industrial sector.

- Hypothesis 3: Implementation of operational strategies positively influences outcomes of R\&D projects in the industrial sector.

- Hypothesis 4: Implementation of quality strategies positively influences outcomes of R\&D projects in the industrial sector.

- Hypothesis 5: Outcomes of R\&D projects have a significant positive effect on the success of market implementation in the industrial sector.

Most previous research has focused on the control of project problems, assuming that the best methods and techniques will lead to better management and thus to successful project performance. However, there are other factors beyond the control of management that could lead to project success. In the literature, these factors are called critical success factors (CSFs). Factors contributing to the success of the project can be grouped into five main categories: factors related to the project, to the project manager, to project team members, to the organization, and factors related to the external environment. Effects of the project strategy on the success of the project have implications not only at operational levels but also at the institutional level. Impact of critical success factors (CSFs) on the success of $R \& D$ projects has been studied, but the focus was not on the association between implementation of project strategies and outcomes of R\&D projects. realizate anterior indică o corelaţie între adoptarea strategiei (incluzând strategii de diferenţiere, cost, operaţionale şi de calitate) şi performanţele proiectului. În plus, cercetările anterioare au concluzionat că performanţa marketingului reflectă succesul extern, iar performanţa proiectului reflectă succesul intern. $O$ analiză a literaturii arată, de asemenea, că succesul proiectului poate fi văzut ca un succes intern care ulterior duce la performanţa marketingului. Pe baza unei literaturi relevante, următoarele ipoteze au fost postulate şi testate:

- Ipoteza 1: Implementarea unei strategii de diferenţiere influenţează în mod pozitiv rezultatele proiectelor C\&D în domeniul industrial.

- Ipoteza 2: Implementarea strategiilor de cost influenţează în mod pozitiv rezultatele proiectelor CDI, în domeniul industrial.

- Ipoteza 3: Implementarea strategiilor operaţionale influenţează în mod pozitiv rezultatele proiectelor C\&D în domeniul industrial.

- Ipoteza 4: Implementarea strategiilor de calitate influenţează în mod pozitiv rezultatele proiectelor C\&D, în domeniul industrial.

- Ipoteza 5: Rezultatele proiectelor C\&D au un efect pozitiv semnificativ în succesul implementării lor pe piaţa din domeniu.

Majoritatea cercetărilor anterioare au pus accentul pe controlul problemelor proiectului, presupunând că metodele şi tehnicile cele mai bune vor duce la un management mai bun şi astfel se va ajunge la proiecte cu performanţe de succes. Totuşi, sunt şi alţi factori în afara controlului managementului care ar putea duce la succesul proiectului. În literatură aceşti factori sunt întâlniţi ca factori critici de succes (CSFs). Factorii care contribuie la succesul proiectului pot fi grupaţi în 5 categorii principale: factori relaţionaţi ai proiectului, ai managerului de proiect, ai membrilor echipei de proiect, ai organizaţiei şi factori relaţionaţi ai mediului extern. Efectele strategiei de proiect în succesul proiectului au implicaţii nu doar la nivelurile operaţionale, ci şi la nivel instituţional. Impactul factorilor critici de succes (CSFs) în succesul proiectelor C\&D a fost studiat, dar fără a se concentra asupra asocierii dintre implementarea strategiilor de proiect şi rezultatele proiectelor C\&D. 


\section{METHODOLOGY}

\section{Research Instrument}

This study was conducted to measure the implementation of project strategy, outcomes of R\&D projects in the industrial sector, and product performance. Participants in the study were identified through a search of public institutions that have developed complex projects whose scientific results were intended for the industrial sector. Target respondents were identified as project managers with extensive experience in project implementation strategy and performance of developing new products, technologies, business models in the industrial sector. In order to obtain a truly representative sample, we took into account not only research institutes, but also various types of organizations that have participated in projects having the role of applicant in the industrial sector, in order to obtain a representative sample.

The survey consisted of four sections:

1) project implementation strategy,

2) the results of the projects and their performance,

3) information on projects,

4) projects in the industrial sector and personal information.

\section{Sample and Method Description}

All public institutions with research department were contacted by telephone or e-mail to identify the manager or person involved in R\&D projects; this approach has helped in the selection of respondents who possess adequate knowledge to properly assess the implementation of project strategy and performance in research and are able to answer all of the survey questions. Answers were collected both on paper and online. More than 200 projects have been investigated and some were not included in the analysis because they contained insufficient information. Finally, 269 responses of the study were used in the analysis. Table 1 shows the characteristics of projects included in the sample. In addition, projects from the industrial sector and profile of respondents are presented in Table 2.

\section{METODOLOGIE}

\section{Instrumentul de cercetare}

Studiul de faţă a fost realizat pentru a măsura punerea în aplicare a strategiei proiectului, rezultatele proiectelor C\&D din domeniul industrial şi performanţa produsului. Participanţii la studiu au fost identificaţi printr-o căutare a instituţiilor publice care au derulat proiecte complexe a căror rezultate ştiinţifice erau destinate domeniului industrial. Respondenţii ţintă au fost identificaţi ca manageri de proiect cu o experienţă bogată în aplicarea strategiei proiectului şi performanţa dezvoltării de noi produse, tehnologii, modele economice în domeniul industrial. În scopul de a obţine un eşantion cu adevărat reprezentativ s-au avut în vedere nu numai institute de cercetare, dar şi diferite tipuri de organizaţii care au participat în proiecte care aveau un rol de aplicant din sectorul industrial, cu scopul de a obţine un eşantion reprezentativ.

Sondajul a fost compus din patru secţiuni:

1) strategia de implementare a proiectului,

2) rezultatele proiectelor şi ale performanţei acestora,

3) informaţii despre proiecte,

4) proiectele din sectorul industrial şi informaţii personale.

\section{Descrierea eşantionului şi a metodei}

Toate instituţiile publice cu departament de cercetare au fost contactate prin telefon sau e-mail pentru a identifica managerul sau persoana implicată în proiectele C\&D. Această abordare a ajutat la selecţia respondenţilor care posedă adecvate cunoştinţe pentru a evalua în mod corespunzător punerea în aplicare a strategiei proiectului şi performanţa în cercetare şi sunt capabili să răspundă la toate întrebările sondajului. Răspunsurile au fost colectate atât în format fizic cât şi online. Mai mult de 200 de proiecte au fost investigate, iar unele nu au fost incluse în analiză, deoarece conţineau insuficiente informaţii. În cele din urmă, 269 de răspunsuri ale studiului au fost utilizate în analiză. Tabelul 1 prezintă caracteristicile proiectelor din eşantion. În plus, proiectele din sectorul industrial şi profilul respondenţilor sunt prezentate în Tabelul 2. 


\section{Survey Design and Measurement of Results}

Measurement scales were developed for each of the variables included in the theoretical model. The evaluated project implementation strategy includes differentiation strategy, cost strategy, operational strategy and quality strategy.

\section{Proiectarea sondajului şi măsurarea rezultatelor}

Scalele de măsurare au fost elaborate pentru fiecare dintre variabilele incluse în modelul teoretic. Strategia de implementare a proiectului evaluată include strategia de diferenţiere, strategia de cost, strategia operaţională şi strategia de calitate.

Table 1: Characteristics of project sample depending on environmental factors

Tabelul 1: Caracteristicile eşantionului proiectelor în funcţie de factorii de mediu

\begin{tabular}{|c|c|c|c|}
\hline $\begin{array}{l}\text { Characteristic } \\
\text { Caracteristică }\end{array}$ & $\begin{array}{l}\text { Class } \\
\text { Clasă }\end{array}$ & $\begin{array}{l}\text { Number } \\
\text { Număr }\end{array}$ & $\begin{array}{l}\text { Project percentage } \\
\text { Procentul proiectelor }\end{array}$ \\
\hline \multirow{4}{*}{$\begin{array}{l}\text { Salary } \\
\text { Salariul }\end{array}$} & $\begin{array}{l}\text { Very satisfactory } \\
\text { Foarte satisfăcător }\end{array}$ & 6 & 2.23 \\
\hline & $\begin{array}{l}\text { Satisfactory } \\
\text { Satisfăcător }\end{array}$ & 147 & 54.65 \\
\hline & $\begin{array}{l}\text { Unsatisfactory } \\
\text { Nesatisfăcător }\end{array}$ & 110 & 40.89 \\
\hline & $\begin{array}{l}\text { Very unsatisfactory } \\
\text { Foarte nesatisfăcător }\end{array}$ & 6 & 2.23 \\
\hline \multirow{4}{*}{$\begin{array}{c}\text { Job satisfaction } \\
\text { Satisfacţia locului de muncă }\end{array}$} & $\begin{array}{l}\text { Very satisfactory } \\
\text { Foarte satisfăcător }\end{array}$ & 8 & 2.97 \\
\hline & $\begin{array}{l}\text { Satisfactory } \\
\text { Satisfăcător }\end{array}$ & 203 & 75.46 \\
\hline & $\begin{array}{l}\text { Unsatisfactory } \\
\text { Nesatisfăcător }\end{array}$ & 54 & 20.07 \\
\hline & $\begin{array}{l}\text { Very unsatisfactory } \\
\text { Foarte nesatisfăcător }\end{array}$ & 4 & 1.49 \\
\hline \multirow{4}{*}{$\begin{array}{c}\text { Job security } \\
\text { Siguranţa locului de muncă }\end{array}$} & $\begin{array}{l}\text { Very satisfactory } \\
\text { Foarte satisfăcător }\end{array}$ & 14 & 5.20 \\
\hline & $\begin{array}{l}\text { Satisfactory } \\
\text { Satisfăcător }\end{array}$ & 190 & 70.63 \\
\hline & $\begin{array}{l}\text { Unsatisfactory } \\
\text { Nesatisfăcător }\end{array}$ & 62 & 23.05 \\
\hline & $\begin{array}{l}\text { Very unsatisfactory } \\
\text { Foarte nesatisfăcător }\end{array}$ & 3 & 1.12 \\
\hline \multirow{4}{*}{$\begin{array}{l}\text { Work programme } \\
\text { Programul de lucru }\end{array}$} & $\begin{array}{l}\text { Short } \\
\text { Scurt }\end{array}$ & 8 & 2.97 \\
\hline & $\begin{array}{l}\text { Regular } \\
\text { Obişnuit }\end{array}$ & 151 & 56.13 \\
\hline & $\begin{array}{l}\text { Long } \\
\text { Lung }\end{array}$ & 81 & 30.11 \\
\hline & $\begin{array}{l}\text { Very long } \\
\text { Foarte lung }\end{array}$ & 29 & 10.78 \\
\hline $\begin{array}{c}\text { Information availability } \\
\text { Disponibilitatea informaţiilor }\end{array}$ & $\begin{array}{l}\text { Sufficient } \\
\text { Suficiente }\end{array}$ & 21 & 7.81 \\
\hline
\end{tabular}


Table 1: Continued

Tabelul 1: Continuare

\begin{tabular}{|c|c|c|c|}
\hline $\begin{array}{l}\text { Characteristic } \\
\text { Caracteristică }\end{array}$ & $\begin{array}{l}\text { Class } \\
\text { Clasă }\end{array}$ & $\begin{array}{l}\text { Number } \\
\text { Număr }\end{array}$ & $\begin{array}{l}\text { Project percentage } \\
\text { Procentul proiectelor }\end{array}$ \\
\hline \multirow{3}{*}{$\begin{array}{c}\text { Information availability } \\
\text { Disponibilitatea informaţiilor }\end{array}$} & $\begin{array}{l}\text { Enough } \\
\text { Destule }\end{array}$ & 182 & 67.66 \\
\hline & $\begin{array}{l}\text { Insufficient } \\
\text { Insuficiente }\end{array}$ & 64 & 23.79 \\
\hline & $\begin{array}{l}\text { Missing } \\
\text { Lipsă }\end{array}$ & 2 & 0.74 \\
\hline \multirow{3}{*}{$\begin{array}{c}\text { Time availability } \\
\text { Disponibilitatea timpului }\end{array}$} & $\begin{array}{l}\text { Realistic duration } \\
\text { Durată realistă }\end{array}$ & 16 & 5.95 \\
\hline & $\begin{array}{l}\text { Average duration } \\
\text { Durată medie }\end{array}$ & 137 & 50.93 \\
\hline & $\begin{array}{l}\text { Unrealistic duration } \\
\text { Durată nerealistă }\end{array}$ & 116 & 43.12 \\
\hline \multirow{3}{*}{$\begin{array}{c}\text { Project complexity } \\
\text { Complexitatea proiectului }\end{array}$} & $\begin{array}{l}\text { High } \\
\text { Ridicată }\end{array}$ & 70 & 26.02 \\
\hline & $\begin{array}{l}\text { Medium } \\
\text { Medie }\end{array}$ & 182 & 67.66 \\
\hline & $\begin{array}{l}\text { Low } \\
\text { Scăzută }\end{array}$ & 17 & 6.32 \\
\hline \multirow{3}{*}{$\begin{array}{l}\text { Work team } \\
\text { Echipa de lucru }\end{array}$} & $\begin{array}{l}\text { High cooperation } \\
\text { Cooperare crescută }\end{array}$ & 159 & 59.11 \\
\hline & $\begin{array}{l}\text { Medium cooperation } \\
\text { Cooperare medie }\end{array}$ & 101 & 37.55 \\
\hline & $\begin{array}{l}\text { Low cooperation } \\
\text { Cooperare scăzută }\end{array}$ & 9 & 3.35 \\
\hline \multirow{4}{*}{$\begin{array}{l}\text { Raw materials for the project } \\
\text { Materii prime şi materiale de proiect }\end{array}$} & $\begin{array}{l}\text { Sufficient } \\
\text { Suficiente }\end{array}$ & 14 & 5.20 \\
\hline & $\begin{array}{l}\text { Enough } \\
\text { Destule }\end{array}$ & 195 & 72.49 \\
\hline & $\begin{array}{l}\text { Insufficient } \\
\text { Insuficiente }\end{array}$ & 52 & 19.33 \\
\hline & $\begin{array}{l}\text { Missing } \\
\text { Lipsă }\end{array}$ & 8 & 2.97 \\
\hline \multirow{7}{*}{$\begin{array}{l}\text { Project duration } \\
\text { Durata proiectului }\end{array}$} & $\begin{array}{l}<3 \text { months } \\
<3 \text { luni }\end{array}$ & 64 & 23.79 \\
\hline & $\begin{array}{l}\text { 3-5 months } \\
\text { 3-5 luni }\end{array}$ & 99 & 36.80 \\
\hline & $\begin{array}{c}\text { 6-8 months } \\
6-8 \text { luni }\end{array}$ & 37 & 13.75 \\
\hline & $\begin{array}{l}\text { 9-11 months } \\
\text { 9-11 luni }\end{array}$ & 39 & 14.50 \\
\hline & $\begin{array}{l}12-17 \text { months } \\
12-17 \text { luni }\end{array}$ & 10 & 3.72 \\
\hline & $\begin{array}{l}\text { 18-23 months } \\
18-23 \text { luni }\end{array}$ & 10 & 3.72 \\
\hline & $\begin{array}{l}>23 \text { months } \\
>23 \text { luni }\end{array}$ & 10 & 3.72 \\
\hline
\end{tabular}


Table 2: Projects in the industrial sector and respondent profile Tabelul 2: Proiectele din sectorul industrial şi profilul respondenţilor

\begin{tabular}{|c|c|c|}
\hline $\begin{array}{l}\text { Variable } \\
\text { Variabila }\end{array}$ & $\begin{array}{l}\text { Category } \\
\text { Categoria }\end{array}$ & $\begin{array}{l}\text { Percentage } \\
\text { Procentul }\end{array}$ \\
\hline \multirow{3}{*}{$\begin{array}{l}\text { Industrial sector } \\
\text { Sectorul industrial }\end{array}$} & $\begin{array}{c}\text { IT } \\
\text { Domeniul IT }\end{array}$ & 38.7 \\
\hline & $\begin{array}{l}\text { Leather } \\
\text { Domeniul pielărie }\end{array}$ & 12.5 \\
\hline & $\begin{array}{c}\text { Chemical products } \\
\text { Domeniul produse chimice }\end{array}$ & 20.0 \\
\hline \multirow{5}{*}{$\begin{array}{l}\text { Position } \\
\text { Poziţia }\end{array}$} & $\begin{array}{l}\text { Manager/deputy manager } \\
\text { Manager/manager adjunct }\end{array}$ & 10.0 \\
\hline & $\begin{array}{l}\text { Assistant manager } \\
\text { Asistent manager }\end{array}$ & 7.5 \\
\hline & $\begin{array}{l}\text { Director } \\
\text { Director }\end{array}$ & 55.0 \\
\hline & $\begin{array}{l}\text { Senior expert } \\
\text { Specialist senior }\end{array}$ & 11.3 \\
\hline & $\begin{array}{l}\text { Senior engineer } \\
\text { Inginer senior }\end{array}$ & 16.3 \\
\hline \multirow{5}{*}{$\begin{array}{l}\text { Age } \\
\text { Vârsta }\end{array}$} & $>45$ & 8.8 \\
\hline & $41-45$ & 25.0 \\
\hline & $36-40$ & 37.5 \\
\hline & $31-35$ & 21.3 \\
\hline & $<31$ & 7.5 \\
\hline \multirow{5}{*}{$\begin{array}{l}\text { Project experience (years) } \\
\text { Experienţa în proiecte (ani) }\end{array}$} & $>20$ & 1.3 \\
\hline & $16-20$ & 11.3 \\
\hline & $11-15$ & 47.5 \\
\hline & $6-10$ & 32.5 \\
\hline & $<6$ & 7.5 \\
\hline \multirow{3}{*}{$\begin{array}{l}\text { Education } \\
\text { Educaţie }\end{array}$} & $\begin{array}{l}\text { Doctoral degree } \\
\text { Diplomă doctor }\end{array}$ & 36.3 \\
\hline & $\begin{array}{l}\text { Bachelor degree } \\
\text { Diplomă de licenţă }\end{array}$ & 51.3 \\
\hline & $\begin{array}{l}\text { Master's degree } \\
\text { Diplomă master }\end{array}$ & 12.5 \\
\hline
\end{tabular}


Elements used to assess project implementation strategy were adapted to evaluate project results. Each item was rated on a 7-point scale, where 1 is strong disagreement and 7 strong agreement.

\section{Content Validity}

Content validity refers to how a measure represents all facets of a given concept. Content validity of the survey in this study was tested through a literature review and interviews with practitioners of new product development. The interviews in the industrial sector included 10 managers of technology.

Four types of strategies were distinguished: differentiation, cost, operational and quality strategies. They were used to investigate the association between R\&D project implementation strategy and their success.

The four types of strategies have also been evaluated by experts to ensure that they are applicable and have substantial effect on R\&D projects.

\section{RESULTS AND ANALYSIS}

\section{Construct Validity}

This study will be used in the literature to develop hypotheses and framework concepts. In order to test the construct validity of the variables in the study, a factor analysis was conducted. The analysis factor, with Varimax rotation, was used to determine the group of differentiation. Only variables with a value greater than 0.5 were extracted [5]. The results suggest that only one factor underlies differentiation strategy. Similarly, only one factor was found to underlie cost strategy, operational strategy and quality strategy. In addition, the results of R\&D projects can be classified into four constructs: performance program, cost performance, quality performance, and innovation. Analysis shows variations of $0.582-0.850$. Finally, only one factor was found primordial for market performance. Figure 1 describes the theoretical model of connections of project implementation strategy with project results and market performance.
Elementele utilizate pentru a evalua strategia de implementare a proiectului au fost adaptate pentru a evalua rezultatele proiectului. Fiecare element a fost evaluat pe o scară de 7 puncte, unde 1 reprezintă dezacord total şi 7 acord puternic.

\section{Validitatea conţinutului}

Validitatea conţinutului se referă la modul în care o măsură reprezintă toate faţetele unui concept dat. Validitatea conţinutului sondajului din acest studiu a fost testat printr-o analiză a literaturii şi interviuri cu practicanţii noi de dezvoltare a produsului. Interviurile din domeniul industrial cuprindeau 10 manageri tehnologi.

Se disting patru tipuri de strategii: de diferenţiere, de costuri, operaţionale şi de calitate. Acestea au fost utilizate pentru a investiga asocierea între strategia de implementare a proiectelor C\&D şi succesul acestora.

Cele patru tipuri de strategii au fost evaluate şi de experţi în domeniu pentru a se asigura că acestea se aplică şi au efect substanţial asupra proiectelor C\&D.

\section{REZULTATELE ŞI ANALIZA}

\section{Validitatea construcţiei}

Acest studiu va folosi în literatura de specialitate pentru a dezvolta ipoteze şi concepte cadru. În scopul de a testa validitatea de construcţie a variabilelor din studiu, s-a realizat o analiză factorială. Factorul de analiză, cu rotaţia Varimax, a fost folosit pentru a decide gruparea de diferenţiere. Singurele variabile cu o valoare mai mare de 0,5 au fost extrase [5]. Rezultatele sugerează că doar un singur factor a stat la baza strategiei de diferenţiere. În mod similar, s-a constatat că doar un singur factor a stat la baza strategiei de costuri, strategiei operaţionale, precum şi strategiei de calitate. În plus, rezultatele proiectelor C\&D se pot clasifica în patru construcţii: performanţa programului, performanţa de cost, performanţa de calitate şi inovaţia. Analiza arată variaţii de 0,582-0,850. În cele din urmă, doar un singur factor a fost găsit primordial pentru performanţa pe piaţă. Figura 1 descrie modelul teoretic dintre legăturile proiectului strategiei de implementare cu rezultatele proiectelor şi performanţa de piaţă. 


\section{Measurement Model and Results}

The "project results" model is a second-order construct. Data were analyzed using AMOS/SPSS. The model was validated to improve the recommended levels shown in Table 3. Based on several studies and results, all scales meet recommended levels. In addition, all constructs had values above 0.7 , suggested by Hair [6] and Nunnaly [7], indicating adequate reliability for each construct. The results provide evidence that the scales are reliable (Table 3).

All values of factors are significant in the statistical level of five percent and exceed the arbitrary standard of 0.5 [8], as shown in Table 4. In addition, all constructs have a mean variation greater than 0.5. Thus, these constructs demonstrate the convergence of validity. The validity assesses whether constructs measure different concepts [6]. The validity of each construct was assessed. First, a procedure recommended by [9] was adopted. Each set of measures was associated with another set of measures. Each model was run twice, once by coercion of correlations between the two constructs to unity and once by releasing this parameter [10]; then a chi-square test was used for differentiation. The results show that the test values are significantly lower for the models with the five percent level, which suggests that these constructs are valid.

\section{Results of the Structural Model Tests}

The model has been created to improve suitability to its recommended levels. Based on several studies resulting from the elimination of some of the elements (including the four elements associated with the cost performance variable), global statistics indicated a very good fit for the model.

Elements associated with cost performance are:

i. the total actual cost of project development was significant within the approved budget;

ii. the actual budget for each phase of the project was essentially the same as the planned budget;

iii. cost objectives were met for projects.

NFI index compared with the TPI index and the goodness of fit index (GFI), with values of 0.930, 0.999 and 0.902, respectively, were all accepted at the level of 0.90 [7]. In addition, the minimum recommended

\section{Modelul de măsurare şi rezultatele}

Modelul "rezultatele proiectelor" este o construcţie de ordinul doi. Datele au fost analizate $\mathrm{cu}$ ajutorul AMOS/SPSS. Validarea modelului a fost realizată pentru a îmbunătăţi nivelurile recomandate, prezentate în Tabelul 3. Pe baza mai multor studii şi rezultate, toate scalele îndeplinesc nivelurile recomandate. În plus, toate construcţiile au avut valori peste nivelul de 0,7 sugerat de Hair [6] şi Nunnaly [7], indicând fiabilitatea adecvată pentru fiecare construcţie. Astfel, rezultatele oferă dovezi că scalele sunt fiabile (Tabelul 3).

Toate valorile factorilor sunt semnificative la nivelul statistic de cinci la sută şi depăşesc nivelul standard de arbitrare de 0,5 [8], aşa cum se arată în Tabelul 4. În plus, toate construcţiile au o variaţie medie mai mare decât 0,5. Astfel, aceste construcţii demonstrează convergenţa termenului de valabilitate. Termenul de valabilitate evaluează dacă construcţiile măsoară diferite concepte [6]. Valabilitatea fiecărei construcţii a fost evaluată. în primul rând, o procedură recomandată de către [9] a fost adoptată. Fiecare set de măsură a fost asociat cu un alt set de măsuri. Fiecare model a fost executat de două ori, o dată prin constrângerea corelaţiilor dintre cele două constructe la unitate şi o dată prin eliberarea acestui parametru [10], apoi a fost folosit un test chi-pătrat pentru diferenţiere. Rezultatele arată că valorile testului sunt semnificativ mai mici pentru modelele ce au nivelul de cinci la sută, ceea ce sugerează că aceste construcţii prezintă valabilitate.

\section{Rezultatele testelor modelului structural}

Modelul a fost realizat pentru a îmbunătăţi potrivirea la nivelurile sale recomandate. Bazat pe mai multe studii care rezultă prin eliminarea unora dintre elemente (inclusiv cele patru elemente asociate cu variabila performanţei de cost), statisticile globale au indicat o potrivire foarte bună pentru model.

Elementele asociate cu performanţe de cost sunt:

i. costul efectiv total de dezvoltare al proiectelor a fost semnificativ în cadrul bugetului autorizat,

ii. bugetul pentru fiecare fază a proiectelor a fost, în esenţă, acelaşi ca şi cel planificat,

iii. obiectivele de cost au fost îndeplinite pentru proiecte.

Indicele (NFI) comparativ cu indicele (TPI) şi indicele de potrivire (GFI), cu valori de 0,930, 0,999 şi 0,902, au fost toate acceptate la nivelul 0,90 [7]. În plus, valoarea minimă recomandată de ajustare a indicelui 
adjustment value of fit index (AGFI $=0.861$ ) was 0.80 . Finally, root mean square error approximation (RMSE) was 0.011 , which was below the 0.08 level recommended by Browne and Cudeck [11].

Test of $\mathrm{H} 1, \mathrm{H} 2, \mathrm{H} 3, \mathrm{H} 4, \mathrm{H} 5$ was based on direct effects (structural coefficients) as shown in Figure 1. H1 proposed a positive relationship between the implementation of the differentiation strategy and project results.

This hypothesis was supported, as the standardized coefficient was 0.39 and statistically significant $(p<0.001)$. H3 proposed a positive result of the relationship between the implementation of the operational strategy and project results. This hypothesis was also supported by a standardized coefficient of $0.41(p<0.01)$. H4 proposed a positive relationship between implementation of quality strategy and project results. This hypothesis was also supported by a standardized coefficient of 0.55 ( $p<$ 0.001). In addition, the direct impact of the project results on market performance is significant (coefficient $=0.49 ; \mathrm{p}<0.001$ ), and therefore, $\mathrm{H} 5$ is supported. However, the coefficient of cost strategy implementation for project outcomes is 0.11 ( $p>0.05$ ). Thus, $\mathrm{H} 2$ is not supported. de potrivire (AGFI $=0.861$ ) a fost de 0,80 . în cele din urmă, eroarea de aproximare a rădăcinii medii pătrate (RMSEA) a fost de 0,011, care a fost sub nivelul de 0,08 recomandat de Browne şi Cudeck [11].

Testul ipotezelor $\mathrm{H1}, \mathrm{H} 2, \mathrm{H} 3, \mathrm{H} 4, \mathrm{H} 5 \mathrm{~s}$-a bazat pe efectele directe (coeficienţii structurali), aşa cum se arată în Figura 1. H1 a propus o relaţie pozitivă între punerea în aplicare a strategiei de diferenţiere şi rezultatele proiectelor.

Această ipoteză a fost susţinută, deoarece coeficientul standardizat a fost 0,39 şi semnificativ din punct de vedere statistic $(p<0,001)$. H3 a propus un rezultat pozitiv între raportul dintre punerea în aplicare a strategiei operaţionale şi rezultatele proiectelor. Această ipoteză a fost susţinută, de asemenea, de un coeficient standardizat de $0,41(p<0,01)$. H4 a propus o relaţie pozitivă între punerea în aplicare a calităţii strategiei şi rezultatele proiectelor. Această ipoteză a fost, de asemenea, sprijinită cu un coeficient standardizat de 0,55 ( $p<0,001)$. În plus, impactul direct al rezultatelor proiectelor pentru performanţele pieţei este semnificativ (coeficient $=0,49$; $\mathrm{p}<0,001)$, şi, prin urmare, $\mathrm{H} 5$ este sprijinit. $\mathrm{Cu}$ toate acestea, coeficientul de implementare a strategiei de cost pentru rezultatele proiectelor este $0,11(p>0,05)$. Astfel, $\mathrm{H} 2$ nu este acceptat.

Table 3: Properties of the main constructs

Tabelul 3: Proprietăţile construcţiilor principale

\begin{tabular}{|c|c|c|c|c|c|c|}
\hline $\begin{array}{c}\text { Measurement } \\
\text { Măsura }\end{array}$ & $\begin{array}{c}\text { Composite reliability } \\
\text { Fiabilitatea compusă }\end{array}$ & $\begin{array}{c}\text { GFI } \\
(>0.90)\end{array}$ & $\begin{array}{c}\text { AGFI } \\
(>0.80)\end{array}$ & $\begin{array}{c}\text { CFI } \\
(>0.90)\end{array}$ & $\begin{array}{c}\text { NFI } \\
(>0.90)\end{array}$ & $\begin{array}{c}\text { RMSEA } \\
(<0.080)\end{array}$ \\
\hline $\begin{array}{c}\text { Differentiation strategy } \\
\text { Strategia de diferenţiere }\end{array}$ & 0.923 & 0.967 & 0.923 & 0.992 & 0.978 & 0.064 \\
\hline $\begin{array}{c}\text { Cost strategy } \\
\text { Strategia de cost }\end{array}$ & 0.852 & 0.923 & 0.821 & 0.910 & 0.908 & 0.076 \\
\hline $\begin{array}{c}\text { Operational strategy } \\
\text { Strategia operaţională }\end{array}$ & 0.905 & 0.925 & 0.850 & 0.950 & 0.926 & 0.075 \\
\hline $\begin{array}{c}\text { Quality strategy } \\
\text { Strategia de calitate }\end{array}$ & 0.919 & 0.985 & 0.924 & 0.993 & 0.988 & 0.070 \\
\hline $\begin{array}{c}\text { Project outcomes } \\
\text { Rezultatele proiectului }\end{array}$ & 0.910 & 0.901 & 0.829 & 0.948 & 0.914 & 0.077 \\
\hline $\begin{array}{c}\text { Market performance } \\
\text { Performanţa pieţei }\end{array}$ & 0.899 & 0.998 & 0.991 & 0.999 & 0.999 & 0.002 \\
\hline
\end{tabular}


Table 4: Items and results of the research model

Tabelul 4: Itemurile şi rezultatele modelului de cercetare

Construct and item

Construcţie şi item

Standardized factor loading Saturaţia factorilor

\begin{tabular}{|c|c|}
\hline \multicolumn{2}{|l|}{$\begin{array}{l}\text { Differentiation strategy (DS) } \\
\text { Strategia de diferenţiere }\end{array}$} \\
\hline $\begin{array}{l}\text { DS1: Provide the customers with high-value project deliverables (products) } \\
\text { DS1: Furnizarea unor livrabile cu valoare înaltă clienţilor (produse) }\end{array}$ & 0.791 \\
\hline $\begin{array}{l}\text { DS2: Develop unique project deliverables (products) } \\
\text { DS2: Dezvoltarea unor livrabile unice (produse) }\end{array}$ & 0.889 \\
\hline $\begin{array}{l}\text { DS3: Develop innovative project deliverables (products) } \\
\text { DS3: Dezvoltarea unor livrabile inovatoare (produse) }\end{array}$ & 0.898 \\
\hline $\begin{array}{l}\text { DS4: Develop highly differential project deliverables (products) } \\
\text { DS4: Dezvoltarea unor livrabile foarte diferenţiate (produse) }\end{array}$ & 0.861 \\
\hline \multicolumn{2}{|l|}{$\begin{array}{l}\text { Cost strategy (CS) } \\
\text { Strategia de cost }\end{array}$} \\
\hline $\begin{array}{l}\text { CS1: Use new technology and equipment that can reduce development cost } \\
\text { CS1: Utilizarea unor noi tehnologii şi echipamente care pot reduce costurile de dezvoltare }\end{array}$ & 0.682 \\
\hline $\begin{array}{l}\text { CS2: Reduce total development cost of the project } \\
\text { CS2: Reducerea costurilor de dezvoltare totale ale proiectului }\end{array}$ & 0.770 \\
\hline $\begin{array}{l}\text { CS3: Improve operational efficiency to minimize development cost } \\
\text { CS3: Îmbunătăţirea eficienţei operaţionale pentru a reduce costurile de dezvoltare la minimum }\end{array}$ & 0.620 \\
\hline $\begin{array}{l}\text { CS4: Be committed to cost control } \\
\text { CS4: Angajarea la controlul costurilor }\end{array}$ & 0.728 \\
\hline \multicolumn{2}{|l|}{$\begin{array}{l}\text { Operational strategy (OS) } \\
\text { Strategia operaţională }\end{array}$} \\
\hline $\begin{array}{l}\text { OS1: Obtain user participation } \\
\text { OS1: Obţinerea participării utilizatorilor }\end{array}$ & 0.686 \\
\hline $\begin{array}{l}\text { OS2: Obtain management support } \\
\text { OS2: Obţinerea sprijinului din partea conducerii }\end{array}$ & 0.714 \\
\hline $\begin{array}{l}\text { OS3: Define the scope of the project } \\
\text { OS3: Definirea sferei de acţiune a proiectului }\end{array}$ & 0.767 \\
\hline $\begin{array}{l}\text { OS4: Plan high quality schedule and update it frequently } \\
\text { OS4: Planificarea unui program de calitate înaltă şi actualizarea frecventă a acestuia }\end{array}$ & 0.785 \\
\hline \multicolumn{2}{|l|}{$\begin{array}{l}\text { Quality strategy (QS) } \\
\text { Strategia de calitate }\end{array}$} \\
\hline $\begin{array}{l}\text { QS1: Focus on quality control } \\
\text { QS1: Concentrarea pe controlul calităţii }\end{array}$ & 0.885 \\
\hline $\begin{array}{l}\text { QS2: Be dedicated to a quality management policy } \\
\text { QS2: Dedicarea faţă de o politică de gestionare a calităţii }\end{array}$ & 0.812 \\
\hline $\begin{array}{l}\text { QS3: Be committed to achieving quality objectives } \\
\text { QS3: Angajarea la obthinerea obiectivelor privind calitatea }\end{array}$ & 0.871 \\
\hline $\begin{array}{l}\text { QS4: Be committed to meeting customer requirements } \\
\text { QS4: Angajarea la îndeplinirea cerinţelor clienţilor }\end{array}$ & 0.725 \\
\hline
\end{tabular}


Table 4: Continued

Tabelul 4: Continuare

\begin{tabular}{|c|c|}
\hline $\begin{array}{l}\text { Construct and item } \\
\text { Construcţie şi item }\end{array}$ & $\begin{array}{l}\text { Standardized factor loading } \\
\text { Saturaţia factorilor }\end{array}$ \\
\hline \multicolumn{2}{|l|}{$\begin{array}{l}\text { Project outcomes-Schedule performance (SP) } \\
\text { Rezultatele proiectului - performanţa programului de lucru }\end{array}$} \\
\hline $\begin{array}{l}\text { SP1: The project team responded quickly to customer needs. } \\
\text { SP1: Echipa proiectului a răspuns prompt nevoilor clienţilor. }\end{array}$ & 0.697 \\
\hline $\begin{array}{l}\text { SP2: All project assignments were proceeding as planned. } \\
\text { SP2: Toate sarcinile proiectului au decurs conform planulu i. }\end{array}$ & 0.633 \\
\hline $\begin{array}{l}\text { SP3: The schedule for each phase of the project was essentially the same as planned. } \\
\text { SP3: Programul pentru fiecare etapă a proiectului a rămas în esenţă cel planificat. }\end{array}$ & 0.594 \\
\hline $\begin{array}{l}\text { SP4: The project was completed ahead of schedule. } \\
\text { SP4: Proiectul a fost finalizat înainte de termen. }\end{array}$ & 0.521 \\
\hline
\end{tabular}

Project outcomes-Quality performance (QP)

Rezultatele proiectului-performanţa calităţii

QP1: Capabilities of the project's deliverables fit well with customer or user needs.

QP1: Capacităţile livrabilelor proiectului se potrivesc bine cu nevoile clienţilor sau utilizatorilor.

QP2: The project's deliverables complied with the contractual requirements.

QP2: Livrabilele proiectului au respectat cerinţele contractului.

QP3: The project's deliverables met customer expectations.

QP3: Livrabilele proiectului au îndeplinit aşteptările clienţilor.

QP4: The project ran smoothly.

QP4: Proiectul a decurs fără probleme.

Project outcomes-Innovation performance (IP)

Rezultatele proiectului-performanţa inovării

IP1: New methods and inventions were obtained in the project.

IP1: În cadrul proiectului s-au obţinut noi metode şi invenţii.

IP2: Creative deliverables were developed in the project.

IP2: În cadrul proiectului s-au dezvoltat livrabile creative.

IP3: Innovative knowledge and know-how were produced in the project.

IP3: În cadrul proiectului s-au obţinut cunoştinţe şi competenţe inovatoare.

IP4: New professional knowledge and problem solving techniques were generated in the project.

IP4: În cadrul proiectului s-au dezvoltat cunoştinţe profesionale noi şi tehnici de rezolvare a problemelor.

\begin{tabular}{|c|}
0.814 \\
\hline 0.835 \\
\hline 0.810 \\
\hline
\end{tabular}

Market performance (MP)
Performanţa pieţei

MP1: The product accomplished the market share goals set previously to its launching.

MP1: Produsul a îndeplinit obiectivele privind cota de piaţă stabilite înainte de lansarea acestuia.

MP2: The product has met the sales goals.

MP2: Produsul a îndeplinit obiectivele privind vânzările.

MP3: The product was a commercial success in comparison with its principal competitors.

MP3: Produsul a avut succes comercial în comparaţie cu principalele produse concurente.

MP4: The product contributed to strengthen ing relationships with customers.

MP4: Produsul a contribuit la consolidarea relaţiilor cu clienţii.

0.696

0.559

0.594

\begin{tabular}{|l}
0.814 \\
0.903 \\
\hline 0.905 \\
\hline \\
\hline
\end{tabular}


Research results show that the implementation of differentiation, operational and quality strategies can improve the quality of project results in the industrial sector in terms of time of implementation, quality, innovation and performance.

Project managers should develop a comprehensive project strategy to provide guidelines for the method of executing the project. As indicated in Table 4, the project team must develop unique, innovative, and highly differentiated products. In addition, the team must provide high value products to customers. For the operational strategy of implementation, managers should pay attention to involving users in the development of the new product. They should clearly identify the application domain or subdomain of an R\&D project. In addition, project managers should win the support of the implementing organization. Project managers must manage project implementation time and update it frequently to improve performance of the project schedule. Finally, in order to improve project performance, project teams should develop a quality management policy and focus on quality control. They should be dedicated to achieving quality and customer satisfaction.
Rezultatele cercetării arată că punerea în aplicare a strategiilor de diferenţiere, operaţionale şi de calitate pot îmbunătăţi calitatea rezultatelor proiectelor în domeniul industrial în ceea ce priveşte timpul implementării, calitatea, inovaţia şi performanţa.

Astfel, managerii de proiecte ar trebui să dezvolte o cuprinzătoare strategie de proiect pentru a oferi linii directoare pentru modul de executare a proiectului. Cum este indicatîn Tabelul 4, echipa de proiect trebuie să dezvolte produse unice, inovatoare şi extrem de diferenţiate. În plus, echipa trebuie să ofere clienţilor produse cu un grad ridicat de valoare. Pentru strategia operaţională de punere în aplicare, managerii trebuie să acorde o atenţie deosebită pentru a obţine participarea utilizatorilor în procesul de dezvoltare al noului produs. Aceştia ar trebui să defineascăîn mod clar domeniul sau subdomeniile de aplicare al unui proiect C\&D. În plus, managerii de proiect ar trebui să câştige sprijinul organizaţiei pentru implementarea acestora. Managerii de proiect trebuie să gestioneze timpul de implementare a proiectului şi să îl actualizeze frecvent pentru a îmbunătăţi performanţă programului proiectului. În cele din urmă, cu scopul de a îmbunătăţi performanţele proiectului, echipele de proiect ar trebui să dezvolte o politică de gestionare a calităţii şi să se concentreze pe controlul calităţii. Acestea ar trebui să se dedice atingerii obiectivelor de calitate şi de satisfacere a cerinţelor clienţilor.

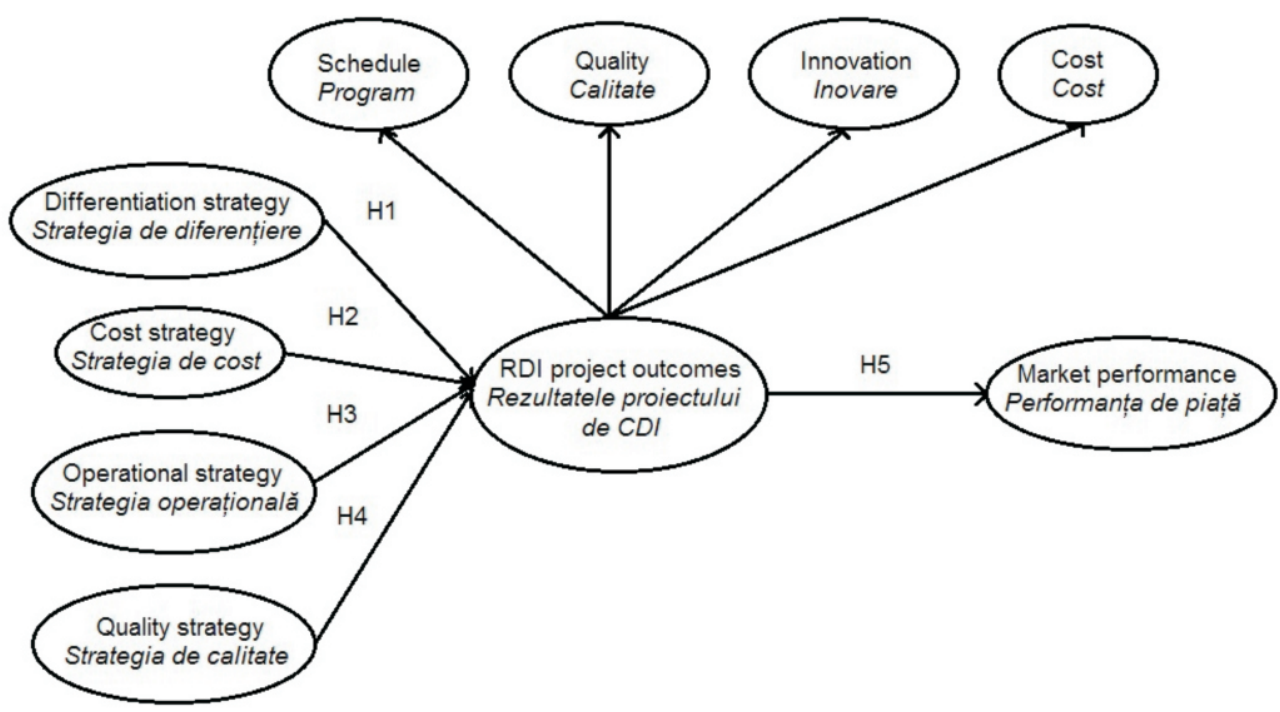

Figure 1. Research model of the project, implementation strategy and estimation of project outcomes through market performance

Figura 1. Modelul de cercetare dintre legăturile proiectului, strategia de implementare şi estimarea rezultatelor proiectelor prin performanţa de piaţă 
As regards the implementation of the differentiation strategy, the project team has given customers high value products to strengthen relations with them. The team tried to develop unique products that were new for the company. As such, they developed innovative and highly differentiated products to achieve market performance.

\section{CONCLUSIONS}

This study validates a framework for assessing project implementation strategy, project results and marketing performance. Research results also provide information regarding how to get R\&D project performance and increase the advantage of the new product developed in the research project on the market.

Research findings indicate that implementing quality, differentiation and operational strategies is associated with R\&D project results in terms of schedule, quality and performance achievement. The research results suggest that strategy implementation involves costs that do not have a significant influence on project results. This indicates that, while the adoption of differentiation, quality and operational strategies is associated with significant results of R\&D projects, the costs of implementing the strategy may be appropriate for some projects. Thus, the need for strategy implementation cost (use of new technology and equipment can reduce development cost, the total cost of project development, improving operational efficiency to minimize development cost, and cost control) may be a specific problem for research projects. In other words, the association of strategy implementation cost and results of the project may depend on variables related to employment status (i.e. satisfaction, job security, working hours and information availability) and variables related to characteristics of the project (ex. time availability, complexity, relationship within the team, availability of materials and supplies, and the project duration). For example, the project duration can act as a moderator between the cost of strategy implementation and results. Projects with a longer duration may involve complicated, uncertain and high risk activities. Such projects usually involve diverse
În ceea ce priveşte implementarea strategiei de diferenţiere, echipa de proiect a oferit clienţilor produse de valoare înaltă pentru consolidarea relaţiilor cu aceştia. Echipa a încercat să dezvolte produse unice, care au fost noi pentru companie. Ca atare, ei au dezvoltat produse inovatoare şi extrem de diferenţiate pentru a realiza performanţa de piaţă.

\section{CONCLUZII}

Acest studiu validează un cadru pentru evaluarea strategiei de implementare a proiectelor, rezultatele proiectelor şi performanţa marketingului. Rezultatele cercetării oferă, de asemenea, indicaţii de a obţine performanţa proiectului C\&D şi de a creşte avantajul noului produs din cercetarea proiectului pe piaţă.

Constatările cercetării indică faptul că implementarea strategiilor de calitate, diferenţiate şi operaţionale este asociată cu rezultatele proiectului C\&D în termeni de program, calitate şi obţinerea performanţei. Rezultatele cercetării sugerează că implementarea strategiei are costuri care nu au o influenţă semnificativă asupra rezultatelor proiectului. Aceasta indică faptul că în timp ce adoptarea unor strategii diferenţiate, de calitate şi operaţionale este asociată cu rezultate semnificative ale proiectelor C\&D, costurile implementării strategiei pot fi adecvate pentru unele proiecte. Astfel, nevoia costului pentru implementarea strategiei (utilizarea de tehnologie şi echipamente noi pot reduce costul de dezvoltare, costul total de dezvoltare al proiectului, îmbunătăţirea eficienţei operaţionale pentru a minimiza costul de dezvoltare, şi conduita controlului costurilor) poate fi o problemă specifică proiectelor de cercetare. Cu alte cuvinte, asocierea dintre costul implementării strategiei şi rezultatele proiectului poate depinde de variabilele legate de starea locului de muncă (ex. satisfacţie, siguranţa locului de muncă, ore de lucru şi disponibilitatea informaţiilor) şi variabilele legate de caracteristicile proiectului (ex. disponibilitatea timpului, complexitatea, relaţia în cadrul echipei, disponibilitatea materialelor şi consumabilelor şi durata proiectului). Spre exemplu, durata proiectului poate acţiona ca un moderator între costul de implementare a strategiei şi rezultatele proiectului. Proiectele cu o durată mai mare pot implica activităţi mai complicate, incerte şi cu un risc mare. Acest tip de proiecte de obicei implică cerinţe diverse şi 
and complex requirements. It is not easy to manage and control the budget for high complexity projects.

Although the study provides important insights on project strategy implementation, there are some limitations. Respondents were identified as managers in research and development departments. In other words, this study employed a narrow functional perspective in analyzing the problem. Although the project managers in research and development departments play an important role in the development of new products, they are not the only stakeholders involved in the development of a new product. Future research may use a broader approach and measures to implement the strategy in terms of the customer, production and marketing groups.

Another limitation is associated with subjective evaluation. The reliability of survey is based on the veracity of respondents and on the expertise of investigators in designing the questionnaire. Respondents may be biased to perceive their own projects as positive, which may influence the evaluations of project success. However, this study was designed to eliminate subjectivity. Although previous studies have argued that subjective measurements allow objective comparisons between organizations acting in different situations, objective measurements should be used in future research to complement subjective measurements. complexe. Nu este uşoară gestionarea şi controlul bugetului pentru proiecte cu o complexitate mare.

Deşi studiul oferă perspective importante asupra implementării strategiei proiectului, există şi unele limite. Respondenţii au fost identificaţi ca manageri în departamentele de cercetare şi dezvoltare. Cu alte cuvinte, acest studiu a angajat o perspectivă funcţională îngustă în analiza problemei. Deşi managerii de proiect în departamentele de cercetare şi dezvoltare joacă un rol important în dezvoltarea noilor produse, nu sunt singurii stakeholderi implicaţi în procesul de dezvoltare al unui nou produs. Cercetările viitoare pot folosi abordări mai ample şi măsuri de implementare a strategiei din punctul de vedere al clientului, al producţiei şi al grupurilor de marketing.

O altă limitare este asociată cu evaluarea subiectivă. Astfel, fiabilitatea sondajului se bazează pe veridicitatea respondenţilor şi competenţa investigatorilor în proiectarea chestionarului. Respondenţii pot fi părtinitori către a percepe proiectele lor ca fiind pozitive, ceea ce poate influenţa evaluarea succesului proiectelor. $\mathrm{Cu}$ toate acestea, acest studiu a fost proiectat astfel încât să elimine subiectivismul. Deşi cercetări anterioare au argumentat că măsurările subiective permit comparaţii obiective între organizaţii ce acţionează în diferite situaţii, măsurările obiective ar trebui să fie folosite în cercetările viitoare pentru a completa măsurările subiective.

\section{REFERENCES}

1. Artto, K., Kujala, J., Dietrich, P., Martinsuo, M., What is project strategy?, Int J Proj Manage, 2007, 26, 1, 4-12.

2. Anderson, D.K., Merna, A., Project management strategy - project management represented as a process based set of management domains and the consequences for project management strategy, Int J Proj Manage, 2003, 21, 7, 387-393.

3. Qureshi, T.M., Warraich, A.S., Hijazi, S.T., Significance of project management performance assessment (PMPA) model, Int J Proj Manage, 2009, 27, 4, 378-388.

4. Thompson, R.L., Smith, H.J., lacovou, C.L., The linkage between reporting quality and performance in IS projects, Information Management, 2007, 44, 2, 196-205.

5. Hair, J.F., Anderson, R.E., Tatham, R.L., Black, W.C., Multivariate Data Analysis with Readings, 4th ed., Prentice Hall International, New Jersey, 1995.

6. Hair, J.F., Black, W.C., Babin, B.J., Anderson, R.E., Tatham, R.L., Multivariate Data Analysis, 6th ed. Prentice-Hall, Upper Saddle River, New Jersey, 2006.

7. Nunnally, J.C., Psychometric Theory, 2nd ed. McGraw-Hill, New York, 1978.

8. Fornell, C., Larcker, D.F., Evaluating structural equation models with unobservable variables and measurement error, Journal of Marketing Research, 1981, 18, 1, 39-50. 
9. Bagozzi, R.P., Yi, Y., Phillips, L.W., Assessing construct validity in organizational research, Adm Sci Q, 1991, 36, 3, 421-458.

10. Li, T., Cavusgil, T., Decomposing the effects of market knowledge competence in new product export, Eur J Marketing, 2000, 34, 1, 57-80.

11. Browne, M.W., Cudeck, R., Alternative Ways of Assessing Model Fit, in: Bollen, K., Long, J., eds. Testing Structural Equation Models, Sage, Newbury Park, CA, 1993.

Article received/Data primirii articolului: 01.10.2014

Accepted/Acceptat la data: 13.12.2014 